\title{
A Brief Note on a Psychotherapeutic Technique Described by Glover and Its Application During Psychiatric Residency
}

\author{
Emanuel E. Garcia, MD \\ Institute of Pennsylvania Hospital, Philadelphia
}

Follow this and additional works at: https://jdc.jefferson.edu/jeffjpsychiatry

Part of the Psychiatry Commons

Let us know how access to this document benefits you

\author{
Recommended Citation \\ Garcia, MD, Emanuel E. (1987) "A Brief Note on a Psychotherapeutic Technique Described by Glover and \\ Its Application During Psychiatric Residency," Jefferson Journal of Psychiatry. Vol. 5 : Iss. 2 , Article 10. \\ DOI: https://doi.org/10.29046/JJP.005.2.007 \\ Available at: https://jdc.jefferson.edu/jeffjpsychiatry/vol5/iss2/10
}

This Article is brought to you for free and open access by the Jefferson Digital Commons. The Jefferson Digital Commons is a service of Thomas Jefferson University's Center for Teaching and Learning (CTL). The Commons is a showcase for Jefferson books and journals, peer-reviewed scholarly publications, unique historical collections from the University archives, and teaching tools. The Jefferson Digital Commons allows researchers and interested readers anywhere in the world to learn about and keep up to date with Jefferson scholarship. This article has been accepted for inclusion in Jefferson Journal of Psychiatry by an authorized administrator of the Jefferson Digital Commons. For more information, please contact: JeffersonDigitalCommons@jefferson.edu. 


\title{
A Brief Note on a Psychotherapeutic Technique Described by Glover and Its Application During Psychiatric Residency
}

\author{
Emanuel E. Garcia, M.D.
}

Few would dispute the existence of a general tendency to blame psychological ailments on physical problems. For example, we often attribute changes in mood to the somatic effects of the weather, irritability to diet, apathy to physical exhaustion, etc. How many of us can deny at some time having attempted to explain to our spouses that an outburst of temper was really the fault of our indigestion, let us say? Of course, our spouses are rather skeptical. And as psychiatrists we too preserve a skepticism towards the explanations of this kind which our patients so often provide. This is not to say that we render meaningless the influence of somatic factors on the psyche, but only to acknowledge that unconscious processes operate in devious and wily ways, and that a psychological principle independent of these psychosomatic relations seems to be hard at work. In extreme cases, excessive and overriding concern for physical status is unequivocally indicative of a major psychiatric disturbance-and the processes of denial and displacement are observable in purer culture, as it were. But we must not ignore the attempt at self-cure inherent in such tendencies, the acknowledgment of which might lead to efficacious therapeutic interventions. Indeed, as resident psychiatrists, circumstances permit us to practice a type of brief psychotherapy which has long been utilized, albeit in an uncomprehending, intuitive manner. Glover (1931) had laid the theoretic groundwork for the technique I am about to describe, in his brilliant and far-reaching paper on inexact interpretation (the perusal of which is strongly recommended to the reader), which consequently warrants a brief discussion.

In the course of investigating the therapeutic successes brought about by psychoanalysis during its early stages of development as a therapy and science, Glover provides a valuable delineation of the differences between psychoanalysis proper and all other psychotherapies. The latter (which includes analyticallyoriented therapy) have in common a fundamental reliance on suggestion, which consequently distinguishes them from the "truth therapy" offered by psychoanalysis proper. K. R. Eissler similarly distinguishes therapies which aim for a change in psychic structure, i.e., psychoanalysis, from those whose aim is a

Dr. Garcia is a second-year resident at the Institute of Pennsylvania Hospital, Philadelphia, Pennsylvania. 
change in content, i.e., all other therapies. He defines their respective endpoints as follows:

A structural change... is an internal change which leads to mastery. It is a change performed in and on the ego in respect to extending its area of capacity mainly by the elimination of certain defense mechanisms. A change of content is a rechannelizing of energy based on displacement, or new repressions, or on an exchange of illusions, or the building up of magical beliefs, or on imitation.... It is of paramount importance to keep in mind that extensive changes of content are possible without changes of structure (1950, p. 117).

After reminding us that neurotic symptoms are spontaneous attempts at self-cure, Glover notes that "whatever psychotherapeutic process is not purely analytical must, in the long run, have something in common with the processes of symptom-formation" (p. 404). In other words, here the therapist aims to restore psychic equilibrium by shoring up crumbling defenses and creating a more adequate, less disquieting ego-syntonic symptom. Of course, here we are referring to symptoms as, in essence, compromise formations between pressing instinctual forces and the defenses against them. I am not convinced that the entire range of psychopathologic symptomatology in the psychoses can be fully explained by this formulation, as Arlow and Brenner (1964, pp. 144-178) seem to assert. But if one accepts the general findings of psychoanalysis, one can scarcely dispute the universal application of this fundamental formulation to the human mind.

The method of "neglect and counter-stimulation," typically employed by the unwitting general medical practitioner, is of particular interest. Glover describes it as follows:

The psychological truth is not even brushed aside; it is completely ignored. Nevertheless, stimulated no doubt by intuitive understanding of counter-irritations and attractions, the practitioner recommends his patient to embark on activities outside his customary routine. The physician unwittingly tries to reinforce the mechanism of repression (neglect) and quite definitely invokes a system of counter-charges, or anticathexis. He advises a change of place (holiday) or of bodily habit (recreation, sport, etc.) or of mental activity (light reading, music-hall, etc.). . . . His advice to go for a holiday or play golf or attend concerts is therefore an incitement to substitute (symptom) formation. And on the whole it is a symptom of the obsessional type. The patient must do or think something new (obsessional ceremonial or thought), or take up some counter attraction (anticathexis, cancellation, undoing, expiation). This countercharge system no doubt contributes to the success of the general manoeuvre but the repression element is important. The physician encourages the patient by demonstrating his own capacity for repres- 
sion. He says in effect, 'You see, I am blind; I don't know what is the matter with you: go and be likewise.' (p. 405)

Notwithstanding the apparent complexity of the above passage and its use of specialized terms that require a more than casual familiarity with analytic thought, an awareness of the principles cited by Glover can prove valuable, particularly in the management of certain fairly common situations of crisis in the psychiatric hospital. At this juncture a few examples are necessary.

\section{CASE NO. 1}

A 27-year-old woman with a provisional diagnosis of borderline personality disorder, who had been transferred two days previously from a nearby psychiatric facility after attempting suicide, was demanding to leave the hospital. After the nursing staff had exhausted their persuasive skill, I was called to decide about committing the patient involuntarily. The patient did not appear to be psychotic when I saw her. Nor was she amenable to a rational discussion of her difficulties and the sudden impulse to end treatment. Her (new) attending psychiatrist was unavailable until morning. As the psychiatric house officer on call I considered it my primary task to have the patient defer her decision until she could consult personally with her attending.

During the course of my initially fruitless attempt to engage the patient in a meaningful dialogue, I happened to notice that her left hand was swollen. I inquired with concern about its cause, and the patient related that she had suffered trauma two days ago while being placed in restraints at the other psychiatric hospital. An X-ray had yet to be taken, a fact to which I responded with grave surprise. After examining the hand in a rather meticulous manner, I communicated my worry about the existence of a fracture, and stressed the need for an X-ray. Interestingly, from that point on she began to feel free enough to relate a host of complaints. She claimed, for example, that the special restrictions under which she had been placed were preventing her from ministering in her usual way to the severe headache from which she suffered by isolating herself in a dark and quiet room. The forthcoming information provided the basis for a compromise, which occasioned the patient to withdraw in writing her demand to leave. I prescribed a nonsteroidal agent, ordered that her hand be immobilized and her arm set in a sling, and sent her for an immediate radiograph to rule out fracture. The remainder of the day was uneventful. Incidentally, the hand was not fractured.

\section{CASE NO. 2}

I was summoned by the experienced nursing staff of a drug and alcohol rehabilitation unit to sign a patient out of the hospital against medical advice. The staff assured me that they had done their best to persuade the patient to 
stay, and expressed great skepticism that a relative neophyte could succeed where they had failed.

The patient in question was a middle-aged woman with a long history of codeine addiction. I had been notified approximately two hours beforehand that her blood pressure was elevated $(150 / 120)$; at that time an evaluation of her medication schedule revealed a precipitous decrease in codeine dosage from the day before (the dose had been halved). I concluded that an incipient withdrawal state was responsible for the hypertension, and consequently prescribed additional codeine and instituted a gentler taper. By the time of the second call, I was informed that the patient refused to comply with the revised codeine regimen (!) and, with the cooperation of her husband (a physician), was in the process of departing.

Despite suffering from withdrawal symptoms, she was lucid and fully oriented. Though somewhat agitated, her thought processes seemed reasonably logical. She greeted me with a withering stare and stated expressly that the last thing she wanted was "psychology." She was simply sick and tired of talking, and she felt that the hospital environment was not conducive to her welfare. She had the full support of her husband to return home. I believe that a forensic psychiatrist would have had no hesitation in declaring her fully competent to make such a decision.

I briefly acknowledged the validity of her feelings, but proceeded to express concern for her physical well-being. I performed a careful physical examination, paying special attention to her blood pressure, which I measured several times. In response to these maneuvers, she softened and quieted, and was able to entertain my subsequent remarks. I stressed the importance of controlling her blood pressure, as well as her need to comply with the prescribed medical regimen. I even attempted to relate her misgivings about remaining in the hospital to her physiological state, which I declared required immediate and expert attention of the sort that our hospital was equipped to provide. She agreed not to depart until she could meet with her attending psychiatrist in the morning, by which time I assured her that her blood pressure would be well-controlled. Later that night I made a point of personally rechecking her pressure; it was, in accordance with her general mental condition, significantly improved.

\section{DISCUSSION}

It goes without saying that any psychotherapeutic intervention occurs within a matrix of many variables, making it extraordinarily difficult to single out the chief contribution to success or failure. Even under the "laboratory" conditions of psychoanalysis this holds true. (See Waelder [1962] for a general discussion of scientific exactitude in the so-called "inexact" sciences such as psychoanalysis.) Nevertheless it remains an essential part of our task to continue 
our investigatory efforts into the specifics of our work. Eissler provides an especially enlightening example, which can serve as an ideal. With keen scrutiny he convincingly traces a patient's abandonment of a promising career as a concert pianist to a chance expression of confidence in the patient's ability uttered at the end of the final therapeutic session. Eissler was forced to conclude that with his brief comment he had imposed an overburdening responsibility on the youth, incurring in him the feeling that he could not live up to his therapist's expectations (1978, pp. 505-506).

For the cases described above, one could conceivably credit any one of many factors with the responsibility for success, e.g., the cordial civility and sympathetic understanding with which I attempted to address myself to the patients; the general hospital ambience; the pressure (overt or tacit) of the patients' peers or of the staff; the simple passage of time, etc. Even the apparently mundane must be included, since under special conditions certain details may acquire a powerful, if idiosyncratic, psychological meaning. The peculiarities of my dress or manner, or the configuration of my facial features might have been of decisive importance. However, as I examine these cases retrospectively - and I must stress that my interventions were guided at the time by pure intuition-I become convinced that the decisive points centered upon the operation of the basic process described by Glover (which I will illustrate in more detail in a moment).

If we examine more closely Glover's example of neglect and counterstimulation we see that Glover has excluded an important intermediary step: the patient's initial attempt at self-cure via symptom-formation in the face of a breakdown of defenses or increasing dystonicity of pre-existing symptomatology. The psychologically troubled individual has consulted the general medical practitioner in essence to confirm his own magical attribution of psychic conflict to physical illness. He is saying: "Please set my mind at rest by diagnosing a medical condition that explains my anxiety." Psychology is wishfully ignored. The practitioner, once he has failed to discover an explanatory medical condition, does the "next best thing." He reinforces the patient's neglect of the psychological truth by laying the blame for mental discomfort on certain environmental factors or work habits, etc., and he recommends "undoing" them.

For the cases I have reported, the patients were already prescribing their own change of scenery which, unfortunately, would have ultimately resulted in a great deal of harm. I merely refocused their attention from environmental causes of their anxiety to somatic ones. Like Glover's practitioner, I served as an unwitting accomplice in substitute symptom-formation, aiding repression while offering a counter-attraction. This redirection was in retrospect merely a return to what must have been their first, perhaps unconscious, step in ministering to themselves. In fact, I would go so far as to assert that the initial substitutesymptom or "inexact interpretation" created in response to psychic conflict is always somatic. And although the somatic interpretation may in time consciously 
be given up-after a physical disorder has effectively been ruled out, or when mental symptoms persist despite appropriate medical treatment for a diagnosed disorder-unconsciously it never dies. It is immortal, ever ready to be of use to our innately truth-avoiding minds. That first step of somatic interpretation follows a path of least resistance for the psyche-and for good reason. After all, during the earliest stages of individual development the slightest disruption of somatic homeostasis, e.g., lack of warmth, delay of hunger-gratification, illness or overt trauma, results in extreme, sometimes overwhelming, displeasure. Psychology in the infant or child is inextricably dependent on bodily function. Physical sensation forms the bedrock upon which our mental apparatus is elaborated and organized. ${ }^{1}$ In the adult, the subtle and highly refined psychological experiences of love are at bottom always associated with the maternal protection and nurturance of infancy. Nevertheless, despite the logical developmental precedent for suspecting somatic disturbances to cause all mental dysfunction, we cannot overlook the mind's tendency to turn away from psychological truth by taking advantage of such a phenomenon.

The other aspect of the "neglect and counter-stimulation" technique which Glover fails to touch upon is the actual laying on of hands. This practice, which has been employed for ages, has had a good deal of success considering the not inconsiderable number of physical and mental cures reported to have occurred in times when medical ignorance was the rule of the day. Freud cites, for example, the many cures of scrofula attributed to the healing power of the royal touch during the reigns of Charles I and Charles II of England (1913, p. 42). The dependent relation of the patient (strictly speaking, one who suffers) to the physician obviously recalls that of child to mother; the very physical physical examination is no doubt reminiscent of the mother's early nuturing ministrations (though it may sometimes be interpreted as a hostile or sadistic act, depending on a patient's particular constitution, development and psychological state).

I should like to call special attention to the laying on of hands as a "positive transference stimulus." Insofar as it can evoke feelings of infantile reassurance, it is probably the quickest route to the establishment of a positive transferential relationship. And as such, it becomes an ideal tool in the crisis situation, particularly when the physician is essentially a stranger. Whereas in our culture physical demonstrations of affection between strangers are usually unacceptable, a physician's formal physical evaluation is not. Sometimes even a wildly paranoid patient will pay deference to the physician's task and submit to an exam without incident, though he might recoil from a handshake offered by someone else. The laying on of hands consequently primes the patient to follow the physician's suggestions. Furthermore, while the gentle manipulation of the

\footnotetext{
${ }^{1}$ Nearly the whole of Freud's opus can be cited to support this. For a general example, see the "Three Essays on the Theory of Sexuality" (1905). However, more than a fragmentary discussion of this immense topic is far beyond our scope here.
} 
patient's body serves to evoke the dependence and blissful trust of infancy, the physician's serious attention to the details of the exam concomitantly confirms, if only temporarily, the patient's magical somatic interpretation. And when the physician pronounces in favor of a physical disturbance, then a powerful harmony of forces is achieved, which can render the patient quite suggestible.

In case number one I was lucky enough to direct attention to a physical abnormality (the swollen, possibly fractured hand), and by pressing for an immediate medical work-up "proved" to the patient my conviction that her troubles were somatic. I thus provided for her an explanation, or interpretation, sufficiently inexact to serve as a temporary solution of her mental conflict. This facilitated a more reasonable verbal exchange which ultimately led to a satisfactory compromise. The slight displacement produced a significant change.

In case number two the patient allowed me no other course than a physical approach, simply because she expressly refused to discuss anything at all. But she too came around in response to the somatically modified method of neglect and counter-stimulation. To the objection that the existence of a codeine withdrawal state would render psychological inferences invalid, I would offer the response that even under such stresses an individual's psychology does not simply evaporate, as Engel and Romano noted in their classic paper on delirium (1959). As long as a reasonably intact ego was in operation-as I judged to be the case-then psychotherapeutic maneuvers were justified. To a second possible objection that the lack of codeine was the only souce of the psychological disruption, I make the reply that my ministerings should therefore have been utterly without effect. However, the patient did indeed calm down and prove amenable to my advice to comply with her medical regimen and defer any decisions about leaving the hospital until she could discuss the pertinent issues with her attending psychiatrist.

The turning points in the management of both cases occurred after I had assumed the role of the general practitioner by focusing on physical symptomatology while implying a neglect for the psychological. I was able to strengthen their defensive structures sufficiently to prevent the more dangerous solutions which they advocated for themselves from materializing.

I am well aware of the shortcomings, complexities and unanswered questions raised by the cases presented. Most importantly, the core conflicts presumed to be the basis for the patients' distress remain unknown. Certainly the unconscious realms of the patients' minds were not available to me, so intrapsychic extrapolation is highly speculative at best. Nevertheless, Glover's findings permit a valuable perspective. In addition, his insight lends itself to application in the form of a brief psychotherapy which seems particularly well-suited to situations frequently encountered by psychiatric residents.

Because the resident's duties include physical examination and diagnosis (except under the special circumstances of a formal psychotherapeutic relationship which, for transferential reasons, would preclude these activities), he may put the physical exam to good psychotherapeutic use, in the manner I have tried 
to describe. Thus he becomes an original and daring suggestionist, as Glover puts it (p. 410). For many, residency will provide the only opportunity to employ this modest addition to the psychotherapeutic armamentarium. As practicing psychiatrists we will have beaten our stethoscopic swords into the ploughshares of purely verbal technique. This is not to imply that we will neglect the many medical conditions that present themselves to us and that might prove to be of psychological import, or that we will be disregarding the biochemical basis of psychiatric disorders, but only that the majority of us will abandon the timehonored medical practice of the laying on of hands as we concentrate on verbal content and visual observation.

Otto Fenichel claims that brief psychotherapy is a more difficult undertaking than psychoanalysis proper, and that its optimal practice requires full training in psychoanalysis (1954, p. 244). While I happen to agree with him, practicalities make it nearly impossible for brief therapy to be undertaken as he envisioned on all but a rather small scale. So we must make do with our inadequacies and take guidance where we can find it. An understanding of Glover's theoretic formulations enables us at least to experiment with the conscious and rational application of a therapeutic technique uniquely suited to the circumstances of residency training. I have attempted to illustrate its use in two cases, and to elucidate the mechanism underlying its operation. Only the experience of others will define its limitations and either confirm or disconfirm its general utility.

\section{REFERENCES}

Arlow, JA, Brenner C: Psychoanalytic Concepts and the Structural Theory. New York, International Universities Press, 1964

Eissler KR: The Chicago Institute of Psychoanalysis and the sixth period of the development of psychoanalytic technique. Journal of General Psychology 42:103-157, 1950

Eissler KR: Creativity and adolescence: the effect of trauma in Freud's adolescence. Psychoanal Study Child 33:461-518, 1978

Engel GL, Romano J: Delirium, a syndrome of cerebral insufficiency. Journal of Chronic Disease 9(3):260-277, 1959

Fenichel O: Brief psychotherapy, in The Collected Papers of Otto Fenichel, Second Series. New York, W. W. Norton \& Co, 1954, pp 243-259

Freud S: Three essays on the theory of sexuality. Standard Edition, 7:135-243, 1905

Freud S: Totem and taboo. Standard Edition, 13:1-161, 1913

Glover E: The therapeutic effect of inexact interpretation: a contribution to the theory of suggestion. Int J Psychoanal 12:397-411, 1931

Waelder R: Psychoanalysis, scientific method, and philosophy. J Am Psychoanal Assoc 10:617-637, 1962 